\title{
A SIX-ORDER METHOD BASED ON HERONIAN MEAN FOR SOLVING NON-LINEAR EQUATIONS
}

\author{
Manoj Kumar $\operatorname{Singh}^{1} \&$ Arvind K. Singh ${ }^{2}$
}

Abstract- A new variant of Newton's method based on heronian mean has been developed and its convergence has been discussed. The method generates a sequence converging to the root with a suitable choice of initial approximation $x_{0}$. The convergence analysis shows that the proposed method has sixth order of convergence. In terms of computational cost, it requires evaluations of only two functions and two first order derivatives per iteration and the efficiency index of the proposed method is 1.5651. Proposed method has been compared with the methods of Parhi, and Gupta [15] and that of Kou and Li [8]. Method discussed in this paper does not require the evaluation of the second order derivative of the given function as required in the family of Chebyshev-Halley type methods. The efficiency of the method is verified on a number of numerical examples. Method has also been compared with some existing sixth order methods.

Keywords- Newton's method, Iteration function, Order of convergence, Function evaluations, Efficiency index.

\section{INTRODUCTION}

In Science and Engineering, many of the nonlinear and transcendental problems of the form $f(x)=0$, are complex in nature. Since it is not always possible to obtain its exact solution by usual algebraic process, therefore numerical iterative methods such as Newton, secant methods are often used to obtain the approximate solution of such problems. Though these methods are very effective, but there are some limitations that they do not give the result as fast as required and some time methods fails. These methods can also be used to find local maxima and local minima of functions, as these extrema are the roots of the derivative function. Many optimization problems also lead to such equations, since to solve the nonlinear equation problem is equivalent to minimizing a master function described as follows:

(Find: $x, x \varepsilon \varphi$

$\left\{\operatorname{Min} F(x)=f^{2}(x)\right.$

where $\varphi$ is the solution space. This master function is positive definite and has a global minimum at each of the roots. When the minimization of $F(x)$ is 0 , the corresponding $x$ is the exact solution. This paper is concerned with the iterative methods for finding a simple root $\alpha$, i.e. $f(\alpha)=0$, and $f^{\prime}(\alpha) \neq 0$ of $f(x)=0$, where $\mathrm{f}: \mathrm{R} \rightarrow \mathrm{R}$, be the continuously differentiable real function .

Now considering the problem of finding a real zero of a function $f: R \rightarrow R$. This zero can be determined as a fixed point of some iteration function $\mathrm{g}$ by means of the one-point iteration method

$x_{n+1}=g\left(x_{n n}\right), \quad n=0,1_{x} \ldots$

where $x_{0}$ is the starting value, The best known and the most widely used example of these types of methods is the classical Newton's method given by

$x_{n+1}=x_{n}-\frac{f\left(x_{n}\right)}{f\left(x_{n}\right)} \quad n=0,1_{x} \cdots$

It converges quadratically to simple zeros and linearly to multiple zeros. But their convergence and performance characteristics are highly sensitive to the initial guess of the solution supplied to the methods. In the literature, some of its modifications have been introduced in order to accelerate it or to get a method with a higher order of convergence at the expense of additional evaluations of functions, derivatives and changes in the points of iterations. All these modifications are in the direction of increasing the local order of convergence with the view of increasing their efficiency indices. If we consider the definition of efficiency index as $p^{1 / m}$ where $p$ is the order of the method and $m$ is the number of functions evaluations required by the method (units of work per iteration), then the efficiency index of this method is 1.414. Ford et. al. [2] and Gerlach [3] described accelerated Newton's method. The method developed by Fernando et al. [1], called as trapezoidal Newton's method or arithmetic mean Newton's method, suggests for some other variants of Newton's method. Frontini et al [8] developed new modifications of Newton's method to produce iterative methods with third order of convergence and efficiency

\footnotetext{
${ }^{1}$ Department of Mathematics, Institute of Science, Banaras Hindu University, Varanasi-221005, India

${ }^{2}$ Corresponding Author, Department of Mathematics, Institute of Science, Banaras Hindu University, Varanasi-221005, India
} 
index 1.442. With the same efficiency index, Ozban [6], and Traub [10] developed a third order method requiring one function and two first derivatives evaluations per iteration. Chen [9] described some new iterative formulae having third order convergence. Lukic, et al. [7] described Geometric mean Newton method for simple and multiple roots. This paper is concerned with the iterative method for finding a simple and multiple roots. Method presented in this paper requires three functions evaluations per iteration and it is compared with that of T. Lukic [7].

\section{DEFINITIONS}

Definition 1: Considering the problem of numerical approximation of a real root $\alpha$ of the non linear equation:

$$
f(x)=0, \quad f: D \subseteq R \rightarrow R .
$$

The root $\alpha$ is said to be simple if $f(\alpha)=0$ and $f^{\prime}(\alpha) \neq 0$. If $f(\alpha)=f^{\prime}(\alpha)=\cdots=f^{m-1}(\alpha)=0$ and $f^{m}(\alpha) \neq 0$ for $m \geq 1$ then $\alpha$ is of multiplicity $m$.

Definition 2: (See [4]) If the sequence $\left\{x_{n} / n \geq 0\right\}$ tends to a limit $\alpha$ in such a way that

$$
\lim _{x_{n \rightarrow \alpha}} \frac{x_{n+1}-\alpha}{\left(x_{n}-\alpha\right)^{p}}=C=\left|g^{(p)}(\alpha)\right| / p !
$$

for some $C \neq 0$ and $p \geq 1$, then the order of convergence of the sequence is said to be $p$, and $C$ is known as asymptotic error constant.

When $p=1, p=2$ or $p=3$, the sequence is said to convergence lineally, quadratically and cubically respectively.

The value of $p$ is called the order of convergence of the method which produces the sequence $\left\{x_{n}: n \geq 0\right\}$. Let $e_{n}=x_{n}-\alpha$ then the relation $e_{n+1}=C e_{n}{ }^{p}+O\left(e_{n}^{p+1}\right)$ is called the error equation for the method, $p$ being the order of convergence.

Definition 3: See [4] Efficiency index is simply defined as $p^{1 / m}$ where $p$ is the order of the method and $m$ is the number of functions evaluations required by the method (units of work per iteration). Therefore the efficiency index of Newton's method is 1.414 and iterative methods with order of convergence three has efficiency index 1.442

\section{DESCRIPTION OF THE METHODS}

Let $\alpha$ be a simple zero of a sufficiently differentiable function $f$ and consider the numerical solution of the equation $f(x)=0$, see[18], then

$f(x)=f\left(x_{n}\right)+\int_{x_{n}}^{x} f^{\prime}(t) \mathrm{dt}$.

Approximating $f^{\prime}$ by $f^{\prime}\left(x_{n}\right)$ on the interval $\left[x_{n}, x\right]$, we get the value $\left(x-x_{n}\right) f^{\prime \prime}\left(x_{n 1}\right)$ for the integral in (3) and then putting $x=\alpha$ we get

$0 \approx f\left(x_{n}\right)+\left(\alpha-x_{n}\right) f^{\prime}\left(x_{n}\right)$,

and hence, a approximation for $\alpha$, known as Newton's method, is given by

$x_{n+1}=x_{n}-\frac{\left.f\left(x_{n}\right)\right)}{f\left(x_{n}\right)}, \quad n=0,1_{x} \cdots$.

On the other hand, if we approximate the integral in (3) by the trapezoidal rule and then putting $x=\alpha$, we obtain

$0 \approx f\left(x_{n}\right)+(1 / 2)\left(\alpha-x_{n}\right)\left(f^{\prime}\left(x_{n}\right)+f^{\prime}(\alpha)\right)$.

Therefore, a approximation $x_{n+1}$ for $\alpha$ is given by

$x_{n+1}=x_{n}-\frac{2 f\left(x_{n}\right)}{f^{\prime}\left(x_{n}\right)+f\left(x_{n+1}\right)}$.

If the $(n+1)^{\text {th }}$ value of Newton's method is used on the right-hand side of the above equation to overcome the implicit problem, then, we have,

$x_{n+1}=x_{n}-\frac{2 f\left(x_{n}\right)}{f^{\prime}\left(x_{n}\right)+f\left(x_{n+1}\right)}$, where $z_{n+1}=x_{n}-f\left(x_{n}\right) / f^{\prime}\left(x_{n}\right)$

for $n=0,1,2, \cdots$, the trapezoidal Newton's method of Fernando et al. [1]. Rewriting equation (4) as

$x_{n+1}=x_{n}-\frac{f\left(x_{n}\right)}{\left(f^{\prime}\left(x_{n}\right)+f^{\prime}\left(x_{n+1}\right) / f_{2}\right.}, \quad n=0,1_{s} \cdots$,

and further we rewrite as:

$z_{n}=x_{n}-\frac{f\left(x_{n}\right)}{\left(f^{\prime}\left(x_{n}\right)+f^{\prime}\left(y_{n}\right)\right)_{j} / 2}, \quad n=0,1_{s} \cdots$, 
So, this variant of Newton's method can be viewed as obtained by using arithmetic mean of $f^{\prime}\left(x_{n}\right)$ and $f^{\prime}\left(y_{n}\right)$ instead of $f^{\prime}\left(x_{n}\right)$ in Newtons method defined by (1) which was called as arithmetic mean Newton's method.

\subsection{New Variant of Newton's Method}

We know that Heronian-mean of two number $\mathrm{a}$ and $\mathrm{b}$ is given by

$H M(a, b)=\frac{1}{a}(2 A+G)=\frac{1}{a}\{(a+b)+\sqrt{(a b)}\}$.

In (5) if we use the heronian-mean instead of arithmetic mean we get

$y_{n}=x_{n}-\frac{f\left(x_{n}\right)}{f\left(x_{n}\right)}$,

$z_{n}=x_{n}-\frac{a f\left(x_{n}\right)}{f^{\prime}\left(x_{n}\right)+f^{\prime}\left(y_{n}\right)+\operatorname{signf}\left(x_{0}\right) \sqrt{f^{\prime}\left(x_{n}\right) f^{\prime}\left(y_{n}\right)}}$.

Again

$x_{n+1}=z_{n}-\frac{f\left(z_{n n}\right)}{f\left(x_{n}\right)}, \quad n=0,1,2, \ldots$

Now using the linear interpolation on two points $\left(x_{n} f^{\prime}\left(x_{n}\right)\right)$ and $\left(y_{n} v f^{\prime}\left(y_{n}\right)\right)$, we get,

$f^{\prime}(x) \approx \frac{x-x_{n}}{y_{n}-x_{n}} f^{\prime}\left(y_{n}\right)+\frac{x-y_{n}}{x_{n}-y_{n}} f^{\prime}\left(x_{n}\right)$

Thus, we approximate $f^{\prime}\left(z_{n n}\right)$ as:

$f^{\prime}\left(z_{n}\right) \approx \frac{z_{n}-x_{n}}{y_{n}-x_{n}} f^{\prime}\left(y_{n}\right)+\frac{z_{n}-y_{n}}{x_{n}-y_{n}} f^{\prime}\left(x_{n}\right)$,

$f^{\prime}\left(z_{n}\right) \approx \frac{4 f^{\prime}\left(x_{n}\right) f^{\prime}\left(y_{n}\right)-2\left[f^{(}\left(x_{n}\right) x^{\prime}+f^{\prime}\left(x_{n}\right) \operatorname{sign} f^{\prime}\left(x_{0}\right) \sqrt{f^{\prime}\left(x_{n}\right) f^{\prime}\left(y_{n}\right)}\right.}{f^{\prime}\left(x_{n}\right)+f\left(y_{n}\right)+\operatorname{signf} f^{\prime}\left(x_{0}\right) \sqrt{f^{\prime}\left(x_{n}\right) f\left(y_{n}\right)}}$.

Therefore the proposed method can be written as follows:

$y_{n}=x_{n}-\frac{f\left(x_{n}\right)}{f\left(x_{n}\right)}$,

$z_{n}=x_{n}-\frac{a f\left(x_{n}\right)}{f^{\prime}\left(x_{n}\right)+f^{\prime}\left(y_{n}\right)+\operatorname{sign} f^{\prime}\left(x_{0}\right) \sqrt{f^{\prime}\left(x_{n}\right) f^{\prime}\left(y_{n}\right)}}$,

$x_{n+1}=z_{n}-\frac{f\left(x_{n}\right)\left(f\left(x_{n}\right)+f\left(y_{n}\right)+\operatorname{sign} f^{\prime}\left(x_{0}\right) \sqrt{\left.f\left(x_{n}\right) f^{\prime}\left(y_{n}\right)\right]}\right.}{4 f^{\prime}\left(x_{n}\right) f^{(}\left(y_{n}\right)-2\left[f\left(x_{n}\right)\right]^{2}+f^{\prime}\left(x_{n}\right) \operatorname{sign} f^{\prime}\left(x_{0}\right) \sqrt{f^{\prime}\left(x_{n}\right) f^{\prime}\left(y_{n}\right)}}$.

Clearly this method requires evaluations of only two functions $f$ and two derivative $f^{\prime}$ and no second order derivative of $f$.

\section{CONVERGENCE ANALYSIS}

Theorem 1: Let $\alpha \in I$ be a simple zero of a sufficiently differentiable function f: $R \rightarrow R$ for an open interval I. If $x_{0}$ is sufficiently close to $\alpha$, then the methods defined by (12) has six order convergence.

Proof. Since $\alpha \in I$ is a simple zero of $f$, then, we have,

$f\left(x_{n}\right)=f^{\prime}(\alpha)\left[e_{n}+C_{2} e_{n}^{2}+C_{a} e_{n}^{a}+O\left(e_{n}^{4}\right)\right]$, where $C_{j}=\left(\frac{1}{j}\right) f^{(j)}(\alpha) / f^{\prime}(\alpha)$,

$f^{\prime}\left(x_{n}\right)=f^{\prime}(\alpha)\left[1+2 C_{2} e_{n}+3 C_{3} e_{n}^{2}+4 C_{4} e_{n}^{a}+O\left(e_{n}^{4}\right)\right]$.

Now from equations (13), (14), we have,

$\frac{f\left(x_{n}\right)}{f\left(x_{n}\right)}=e_{n}-C_{2} e_{n}^{2}+\left(2 C_{2}^{2}-2 C_{a}\right) e_{n}^{a}+O\left(e_{n}^{4}\right)$.

Therefore, from equation of (12a), we get, $y_{n}=\alpha+\mathrm{C}_{2} e_{n}^{2}+\left(2 C_{3}-2 C_{2}^{2}\right) e_{n}^{\mathrm{a}}+\mathrm{O}\left(e_{n}^{4}\right)$.

Now expanding $f^{\prime}\left(y_{n}\right)$ about $\alpha$, we get,

$f^{\prime}\left(y_{n}\right)=f^{\prime \prime}(\alpha)\left[1+2 C_{2}^{2} e_{n}^{2}+4 C_{2}\left(C_{a}-C_{2}^{2}\right) e_{n}^{a}+O\left(e_{n}^{4}\right)\right]$. 
Since we may easily prove that $f^{\prime}\left(x_{n}\right) f^{\prime}\left(y_{n}\right)>0$ and $\operatorname{sign}\left(f^{\prime}\left(x_{0}\right)\right)=\operatorname{sign}\left(f^{\prime \prime}\left(y_{n}\right)\right)$ holds for $n=0,1,2, \cdots$, therefore, from equations (14) and (15), we get,

$\operatorname{sign}\left(f^{\prime}\left(x_{0}\right)\right) \sqrt{f^{\prime}\left(x_{n}\right) f^{\prime}\left(y_{n}\right)}=f^{\prime \prime}(\alpha)\left[1+C_{2} e_{n}+\frac{1}{2}\left(C_{2}^{2}+3 C_{a}\right) e_{n}^{2}+2\left(C_{2} C_{a}-C_{2}^{a}+4 C_{4}\right) e_{n}^{a}+O\left(e_{n}^{4}\right)\right]$.

Substituting the value of equations (13), (14), (15) and (16) in equation (12b), we get,

$$
\begin{aligned}
& z_{n}= \alpha+e_{n}-\frac{a f^{\prime}(\alpha)\left[e_{n}+C_{2} e_{e}^{2}+C_{3} e_{n}^{3}+O\left(e_{n}^{4}\right)\right]}{a f^{\prime}(\alpha)\left[1+C_{2} e_{n}+\frac{1}{6}\left(5 C_{2}^{2}+9 C_{3}\right) e_{n}^{2}+\frac{1}{2}\left(a C_{2} C_{3}-a C_{2}^{3}+4 C_{4}\right) e_{n}^{3}+O\left(e_{n}^{4}\right)\right]} \\
&= \alpha+e_{n}-\left[e_{n}+C_{2} e_{n}^{2}+C_{a} e_{n}^{a}+O\left(e_{n}^{4}\right)\right] \\
& \times\left[1-C_{2} e_{n}+\frac{1}{6}\left(C_{2}^{2}-9 C_{a}\right) e_{n}^{2}+\frac{1}{6}\left(3 C_{2} C_{a}-13 C_{2}^{a}-2 C_{4}\right) e_{n}^{a}+O\left(e_{n}^{4}\right)\right] \\
& \Rightarrow z_{n}=\alpha+\frac{1}{6}\left(5 C_{2}^{2}+3 C_{a}\right) e_{n}^{a}+O\left(e_{n}^{4}\right) .
\end{aligned}
$$

Now

$$
\begin{aligned}
&\left\{f^{\prime}\left(x_{n}\right)\right\}^{2}=\left\{f^{\prime}(\alpha)\right\}^{2}\left[1+4 C_{2} e_{n}+\left(4 C_{2}^{2}+6 C_{a}\right) e_{n}^{2}+\left(12 C_{2} C_{a}+8 C_{4}\right) e_{n}^{a}+O\left(e_{n}^{4}\right)\right], \\
& f^{\prime}\left(x_{n}\right) \operatorname{sign}\left(f^{\prime}\left(x_{0}\right)\right) \sqrt{f^{\prime}\left(x_{n}\right) f^{\prime}\left(y_{n}\right)}=\left\{f^{\prime}(\alpha)\right\}^{2}\left[1+3 C_{2} e_{n}+\frac{5}{2}\left(C_{2}^{2}+9 C_{a}\right) e_{n}^{2}\right. \\
&\left.+\frac{1}{2}\left(13 C_{2} C_{a}+C_{2}^{a}+6 C_{4}\right) e_{n}^{a}+O\left(e_{n}^{4}\right)\right] .
\end{aligned}
$$

Therefore from equation (11), we have,

$$
\begin{aligned}
& f^{\prime}\left(z_{n}\right) \approx f^{\prime}(\alpha)\left[1+C_{2} e_{n}+\frac{1}{6}\left(5 C_{2}^{2}+9 C_{a}\right) e_{n}^{2}+\frac{1}{6}\left(5 C_{2} C_{a}+C_{2}^{a}+12 C_{4}\right) e_{n}^{a}+O\left(e_{n}^{4}\right)\right] \\
& \times\left[1+C_{2} e_{n}+\frac{1}{6}\left(5 C_{2}^{2}+9 C_{a}\right) e_{n}^{2}+\frac{1}{2}\left(3 C_{2} C_{a}-3 C_{2}^{a}+4 C_{4}\right) e_{n}^{a}+O\left(e_{n}^{4}\right)\right]^{-1} \\
& \Rightarrow f^{\prime}\left(z_{n}\right) \approx f^{\prime}(\alpha)\left[1+\frac{1}{6}\left(5 C_{2}^{a}-4 C_{2} C_{a}\right) e_{n}^{a}+O\left(e_{n}^{4}\right)\right] .
\end{aligned}
$$

Hence from

$x_{n+1}=z_{n 1}-\frac{f\left(z_{n}\right)}{f^{\prime}\left(z_{n}\right)}$, we get,

$x_{n+1}=\alpha+\frac{1}{6}\left(5 C_{2}^{2}+3 C_{a}\right) e_{n}^{a}+O\left(e_{n}^{4}\right)-\frac{f\left(\alpha+\frac{1}{6}\left(5 C_{2}^{2}+a C_{3}\right) e_{n}^{3}+O\left(e_{n}^{4}\right)\right)}{f^{\prime}(\omega)\left[1+\frac{1}{6}\left(5 C_{2}^{3}-4 C_{2} C_{3}\right) e_{n}^{3}+O\left(e_{n}^{4}\right)\right]}$.

Using Taylor's expansion and the fact that $f(\alpha)=0$, we get,

$e_{n+1}=\frac{1}{a 6}\left(5 C_{2}^{2}+3 C_{a}\right)\left(10 C_{2}^{a}-7 C_{2} C_{a}\right) e_{n}^{6}+O\left(e_{n}^{7}\right)$.

This shows that method defined by (12) has six order convergence.

\section{NUMERICAL RESULTS AND CONCLUSION}

In this section, we presented the results of some numerical tests, starting with same initial approximation, to compare with the existing methods.

Example 1: Consider the equation $f(x)=x^{3}+4 x^{2}-10$.

We start with initial approximation $x_{0}=2$. The results obtained by Newton iteration, Maheshwari iteration and present iteration method is shown in Table 1.

Table 1. Comparison of Present method with Newton and Maheshwari method 


\begin{tabular}{|l|l|l|l|l|}
\hline Mathod & $\boldsymbol{x}_{0}$ & $\mathbf{n}$ & $\boldsymbol{x}_{\mathrm{m}}$ & \multicolumn{1}{|c|}{$\boldsymbol{f ( \boldsymbol { x } _ { \mathrm { m } } )}$} \\
\hline Newton method & 2.0 & 1 & 1.500000000000000 & 2.375000000000000 \\
& & 2 & 1.373333333333333 & 0.134345481481482 \\
& & 3 & 1.365262014874627 & $5.284611795151051 \mathrm{e}-004$ \\
& & 4 & 1.365230013916147 & $8.290548692002631 \mathrm{e}-009$ \\
& 5 & 1.365230013414097 & 0.000000000000000 \\
\hline Maheshwari method & 2.0 & 1 & 1.383460112875796 & -0.303737459638828 \\
& & 2 & 1.365230059872621 & $7.671881707693729 \mathrm{e}-007$ \\
\hline Present method & 2.0 & 3 & 1.365230013414097 & 0.000000000000000 \\
& & 2 & 1.365716475678176 & 0.008035061426117 \\
& & 1.365230013414097 & 0.000000000000000 \\
\hline
\end{tabular}

Example 2: Consider the equation $f(x)=x^{a}-e^{-x}$.

We start with initial approximations $x_{0}=1.0$. The results obtained by Newton iteration, Maheshwari iteration and present iteration method is shown in Table 2.

Table 2. Comparison of Present method with Newton and Maheshwari method

\begin{tabular}{|l|l|l|l|l|}
\hline Mathod & $\boldsymbol{x}_{0}$ & $\mathbf{n}$ & $\boldsymbol{x}_{\mathrm{m}}$ & \multicolumn{1}{|c|}{$\boldsymbol{f ( \boldsymbol { x } _ { \mathrm { m } } )}$} \\
\hline Newton method & 2.0 & 1 & 0.812309030097381 & 0.092166771534313 \\
& & 2 & 0.774276548985500 & 0.003144824978613 \\
& & 3 & 0.772884756209622 & $4.050085547491200 \mathrm{e}-006$ \\
& & 4 & 0.772882959152202 & $6.742550962002269 \mathrm{e}-012$ \\
\hline Maheshwari method & 2.0 & 5 & 0.772882959149210 & 0.000000000000000 \\
& & 2 & 0.776281164264182 & 0.007682769461876 \\
& & 3 & 0.772882959509889 & $8.128708817167762 \mathrm{e}-010$ \\
\hline Present method & 2.0 & 1 & 0.77293949149210 & 0.000000000000000 \\
& & 2 & 0.772882959149210 & $1.273931721414434 \mathrm{e}-004$ \\
\hline
\end{tabular}

Example 3: Consider the equation $f(x)=\sin x$.

We start with initial approximations $x_{0}=1.5$. The results obtained by Newton iteration, Maheshwari iteration and present iteration method is shown in Table 3.

Example 4: Consider the equation $f(x)=\sin x-0.5 x$.

We start with initial approximations $x_{0}=1.6$. The results obtained by Newton iteration, Maheshwari iteration and present iteration method is shown in Table 4.

Table 3. Comparison of Present method with Newton and Maheshwari method

\begin{tabular}{|l|l|l|l|l|}
\hline Mathod & $\boldsymbol{x}_{0}$ & $\mathbf{n}$ & $\boldsymbol{x}_{\mathrm{m}}$ & \multicolumn{1}{c|}{$\boldsymbol{f ( \boldsymbol { x } _ { \mathrm { m } } )}$} \\
\hline Newton method & 1.5 & 1 & -12.601419947171721 & -0.035042157161019 \\
& & 2 & -12.566356255118672 & $1.435924050063516 \mathrm{e}-005$ \\
& & 3 & -12.566370614359174 & $-1.286498119741309 \mathrm{e}-015$ \\
\hline Maheshwari method & 1.5 & 1 & -12.140250122502410 & 0.413341334176534 \\
& & 2 & -12.567623187401553 & -0.001252572714845 \\
& & 3 & -12.566370614359172 & $4.898587196589413 \mathrm{e}-016$ \\
\hline Present method & 1.5 & 1 & -0.030027696881139 & -0.030023184609464 \\
& & 2 & $-3.821812658011403 \mathrm{e}-018$ & $-3.821812658011403 \mathrm{e}-018$ \\
\hline
\end{tabular}

Table 4. Comparison of Present method with Newton and Maheshwari method

\begin{tabular}{|l|l|l|l|c|}
\hline Mathod & $\boldsymbol{x}_{0}$ & $\mathbf{n}$ & $\boldsymbol{x}_{\mathrm{m}}$ & $\boldsymbol{f}\left(\boldsymbol{x}_{\mathrm{m}}\right)$ \\
\hline Newton method & 1.6 & 1 & 1.977123551007066 & -0.069983138933437 \\
& & 2 & 1.898950910895084 & -0.002836729003200
\end{tabular}




\begin{tabular}{|l|l|l|l|l|} 
& & 3 & 1.895501147295299 & $-5.635111423818451 \mathrm{e}-006$ \\
& & 4 & 1.895494267061370 & $-2.243205621255129 \mathrm{e}-011$ \\
\hline Maheshwari method & 1.6 & 5 & 1.895494267033981 & 0.000000000000000 \\
\hline Present method & & 2 & 1.925586494937329 & -0.025073843759850 \\
& & 3 & 1.895494852455987 & $-4.794739714153451 \mathrm{e}-007$ \\
& 1.6 & 1 & 1.896139437512832 & 0.000000000000000 \\
\hline
\end{tabular}

Faster convergence of proposed method for example 2 and example 4 are shown in Figure 1 and Figure 2 respectively. The line with green marks (D) shows the proposed method, the line with red marks (C) shows the Maheshwari method and the line with black marks (B) shows the Newton method in the figures.

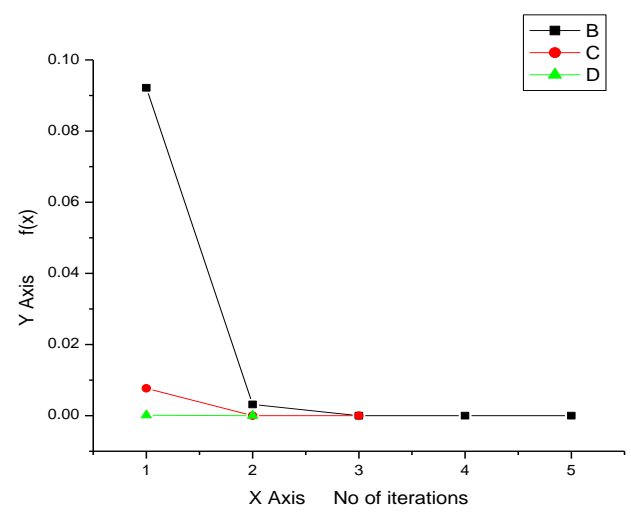

Figure 1

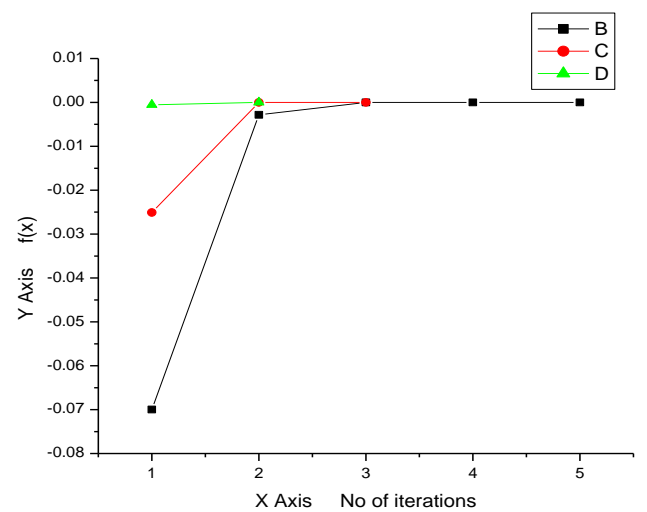

Figure 2

In Table 4, we give the number of iterations $(\mathrm{N})$ and the number of function evaluations (NOFE) required satisfying the stopping criterion, $\mathrm{F}$ denotes that method fails and $\mathrm{D}$ denotes for divergence. PM denotes proposed method. Kou and $\mathrm{Li}$ is the method [8], an improvement of Jarratt method. Gupta denotes for [15] Parhi and Gupta, A sixth order method for nonlinear equations. In Table 4 for simple roots following test functions have been used.
(a) $x^{3}+4 x^{2}-\mathrm{I} 0$,
$\alpha=1.365230013414097$,
(b) $\sin ^{2} x-x^{2}+1$,
$\alpha=-1.404491648215341$,
(c) $x^{3}-10$
$\alpha=2.154434690031884$,
(d) $x^{3}-e^{-x}$
$\alpha=0.772882959149210$,
(e) $x \sin (1 / x)-0.2 e^{-x}$
$\alpha=0.363715708657122$, 
(f) $(x-1)^{3}-1$,

(g) $(x-2)^{23}-1$

$\alpha=2$,

$\alpha=3$.

Table 4 - Comparison with existing sixth order methods

\begin{tabular}{|c|c|c|c|c|c|c|c|}
\hline $\mathrm{F}(x)$ & $x_{0}$ & Kou and $\mathrm{Li}$ & $\begin{array}{l}\mathrm{N} \\
\text { Gupta } \\
\end{array}$ & PM & Kou and $\mathrm{Li}$ & $\begin{array}{l}\text { NOFE } \\
\text { Gupta }\end{array}$ & PM \\
\hline (a) & $\begin{array}{l}-0.5 \\
1 \\
2 \\
\end{array}$ & $\begin{array}{l}15 \\
2 \\
2 \\
\end{array}$ & $\begin{array}{l}62 \\
2 \\
2 \\
\end{array}$ & $\begin{array}{l}3 \\
2 \\
2 \\
\end{array}$ & $\begin{array}{l}60 \\
8 \\
8 \\
\end{array}$ & $\begin{array}{l}248 \\
8 \\
8 \\
\end{array}$ & $\begin{array}{l}12 \\
8 \\
8 \\
\end{array}$ \\
\hline (b) & $\begin{array}{l}-2 \\
-3\end{array}$ & $\begin{array}{l}2 \\
2\end{array}$ & $\begin{array}{l}2 \\
2\end{array}$ & $\begin{array}{l}2 \\
2\end{array}$ & $\begin{array}{l}8 \\
8\end{array}$ & $\begin{array}{l}8 \\
8\end{array}$ & $\begin{array}{l}8 \\
8 \\
\end{array}$ \\
\hline (c) & $\begin{array}{l}-3 \\
2 \\
2.5\end{array}$ & $\begin{array}{l}4 \\
2 \\
2\end{array}$ & $\begin{array}{l}4 \\
2 \\
2\end{array}$ & $\begin{array}{l}4 \\
2 \\
2\end{array}$ & $\begin{array}{l}16 \\
8 \\
8\end{array}$ & $\begin{array}{l}16 \\
8 \\
8\end{array}$ & $\begin{array}{l}16 \\
8 \\
8\end{array}$ \\
\hline (d) & $\begin{array}{l}0.5 \\
1 \\
\end{array}$ & $\begin{array}{l}2 \\
2 \\
\end{array}$ & $\begin{array}{l}2 \\
2 \\
\end{array}$ & $\begin{array}{l}2 \\
2 \\
\end{array}$ & $\begin{array}{l}8 \\
8 \\
\end{array}$ & $\begin{array}{l}8 \\
8 \\
\end{array}$ & $\begin{array}{l}8 \\
8 \\
\end{array}$ \\
\hline (e) & $\begin{array}{l}0.3 \\
0.5 \\
\end{array}$ & $\begin{array}{l}2 \\
2 \\
\end{array}$ & $\begin{array}{l}2 \\
2 \\
\end{array}$ & $\begin{array}{l}2 \\
2 \\
\end{array}$ & $\begin{array}{l}8 \\
8 \\
\end{array}$ & $\begin{array}{l}8 \\
8 \\
\end{array}$ & $\begin{array}{l}8 \\
8 \\
\end{array}$ \\
\hline (f) & $\begin{array}{l}0.1 \\
2.5 \\
3.5\end{array}$ & $\begin{array}{l}5 \\
2 \\
3 \\
\end{array}$ & $\begin{array}{l}4 \\
2 \\
3\end{array}$ & $\begin{array}{l}3 \\
2 \\
3 \\
\end{array}$ & $\begin{array}{l}20 \\
8 \\
12\end{array}$ & $\begin{array}{l}16 \\
8 \\
12\end{array}$ & $\begin{array}{l}12 \\
8 \\
12\end{array}$ \\
\hline (g) & $\begin{array}{l}0.5 \\
1 \\
3.5\end{array}$ & $\begin{array}{l}17 \\
180 \\
5\end{array}$ & $\begin{array}{l}238 \\
10 \\
6\end{array}$ & $\begin{array}{l}15 \\
10 \\
6\end{array}$ & $\begin{array}{l}68 \\
720 \\
20\end{array}$ & $\begin{array}{l}952 \\
40 \\
24\end{array}$ & $\begin{array}{l}60 \\
40 \\
24\end{array}$ \\
\hline
\end{tabular}

Hence from the Table 1, Table 2, Table 3 and Table 4, the main observations are as follows:

I. Proposed method takes lesser number of iterations than the others compared here.

II. Example shows that the Proposed method requires lesser number of functional evaluations, as compared to other methods.

III. The results in the last column of the selected examples, shows the absolute deviation of $f(x)$ in each step with respect to its targeted value, i.e. zero. It can be observed from these examples that the value of absolute error is least for the present method.

Thus, the Proposed method is not only faster but the cost effecting parameters obtain in examples shows that it has minimum cost among all the methods taken here.

\section{CONCLUSION}

We discussed the convergence analysis and compared the efficiency of the proposed method with some existing methods. Numerical computations have been carried out in MATLAB. The stopping criterion has been taken as $\left|x_{n+1}-\alpha\right|+\left|f\left(x_{n+1}\right)\right|<$ $10^{-14}$.

Thus the proposed sixth order method for finding simple real roots of nonlinear equations, is free from second order derivative of the given function, as required in the family of Chebyshev-Halley type methods. Method can also be used to find local maxima and local minima of functions as these extrema are the roots of the derivative function. Method proposed in this paper requires evaluations of two functions and evaluations two first order derivatives per iteration. The convergence analysis of the method is performed to show that the order of convergence of the method is six. The high order convergence is also corroborated by numerical tests

Method has the efficiency index equal to 1.5651, which is better to Newton's method with efficiency index equal to 1.414 and the classical third order methods (1.442), such as Weerakoon and Fernando method, Chebyshev's method, Halley's method and Super-Halley method, fifth order method (1.495) of Kou, Li, Wang [9] and Grau, Noguera [4] and six order method (1.565) of Parhi and Gupta [15] and Kou and Li [8]. The method is tested on a number of numerical examples. On comparing our results with the existing methods, it is found that the present method is most effective as it converges to the root much 
faster. When compared with the sixth order methods of Parhi, Gupta, [15] and Kou and Li [8], proposed method behaves either similarly or better on the examples considered.

\section{REFERENCES}

[1] C. Chun, Some improvements of Jarratt's method with sixth-order convergence, Appl. Math. Comput. 190 (2007) $1432-1437$.

[2] J. Chen, Some new iterative methods with three-order convergence, Appl. Math. Comput. 181 (2006) 1519-1522.

[3] M. Frontini, E. Sormani, Some variant of Newton's method with third-order convergence, Appl. Math. Comput. 140 (2003) $419-426$.

[4] M. Grau, M. Noguera, A variant of Cauchy's method with accelerated fifth-order convergence, Appl. Math. Lett. 17 (2004) 509-517.

[5] M.K.Jain, S.R.K. Iyengar, and R.K. Jain, Numerical Methods for Scientific and Engineering Computation New York, NY: Halsted Press, 1985.

[6] J. Kou, X. Wang, Sixth-order variants of Chebyshev-Halley methods for solving non-linear equations, Appl. Math. Comput. 190 (2007) 1839-1843.

[7] J. Kou, On Chebyshev-Halley methods with sixth-order convergence for solving non-linear equations, Appl. Math. Comput. 190 (2007) 126-131.

[8] J. Kou, Y. Li, An improvement of Jarratt method, Appl. Math. Comput. 189 (2007) 1816-1821.

[9] J. Kou, Y. Li, X. Wang, Some modifications of Newton's method with fifth order convergence, Journal of Computational and Applied Mathematics 209 (2009) 146-152.

[10] T. Lukic, N.M. Ralevie, Geometric mean Newton's method for simple and multiple roots, Applied Mathematics Letters 21,(2008) 30-36.

[11] A.K. Maheshwari, A fourth-order iterative method for solving non-linear equations, Applied Mathematics and Computation 211 (2009) 383-391]

[12] A.M. Ostrowski, Solution of Equations and Systems of Equations, Academic Press Inc., 1966.

[13] J.M. Ortega, W.C. Rheinboldt, Iterative Solution of Nonlinear Equations in Several Variables, Academic Press, New York, 1970.

[14] A.Y. Ozban, Some new variants of Newton's method, Applied Mathematics Letters 17, (2004), 677- 682.

[15] S.K. Parhi, D.K. Gupta, A sixth order method for nonlinear equations, Applied Mathematics and Computation 203 (2008) 50-55

[16] J.R. Sharma, R.K. Guha, A family of modified Ostrowski methods with accelerated sixth order convergence, Appl. Math. Comput. 190 (2007) 111-115.

[17] J.F. Traub, Iterative Methods for the Solution of Equations, Prentice Hall, Clifford, NJ, 1964.

[18] S. Weerakoon, T.G.I. Fernando, A variant of Newton's method with accelerated third-order convergence, Appl. Math. Lett. 13 (2000) 87-93. 